\title{
LOCAL de ABSorÇÃo de Fomesafen Como Mecanismo de RESISTÊNCIA EM BIÓTIPO DE Euphorbia heterophylla RESISTENTE AOS INIBIDORES DA PROTOX ${ }^{1}$
}

\author{
Fomesafen Absorption Site as a Mechanism of Resistance in an Euphorbia heterophylla \\ Biotype Resistant to PROTOX Inhibitors
}

TREZZI, M.M. ${ }^{2}$, VIDAL, R.A. ${ }^{3}$, KRUSE, N.D. ${ }^{4}$, SILVA, R.P. ${ }^{5}$, GUSTMANN, M.S. ${ }^{5}$ e FRANCHIN, E. ${ }^{6}$

\begin{abstract}
RESUMO - Três experimentos foram realizados para verificar se o local de aplicação de fomesafen, folhas ou solo, afeta a eficácia desse herbicida em biótipos de E. heterophylla resistente e suscetivel a ele; e determinar quais estruturas da planta são mais importantes no processo de absorção desse herbicida. Nos dois primeiros experimentos, testaram-se curvas de dose-resposta de fomesafen em biótipos com e sem resistência a inibidores da PROTOX, em pré-emergência (primeiro experimento) e em pós-emergência (segundo experimento). No terceiro experimento, diferentes locais de deposição de fomesafen foram avaliados, por meio do método de vaso duplo, para verificar quais as estruturas das plantas de E. heterophylla mais importantes na absorção do herbicida. Os resultados, em geral, indicam menor eficiência de controle quando o fomesafen é aplicado na parte aérea das plantas de E. heterophylla resistentes a esse herbicida, em comparação às suscetiveis, e que as diferenças entre os biótipos foram menores na aplicação em pré-emergência. Detectou-se maior eficiência do herbicida fomesafen aplicado ao solo quando este foi colocado junto à parte aérea emergente das plantas suscetiveis e resistentes do que junto ao sistema de raizes destas. Esses resultados apóiam a hipótese de que diferenças foliares entre plantas resistentes e suscetiveis podem dificultar a absorção de fomesafen nos biótipos resistentes aos inibidores da PROTOX.
\end{abstract}

Palavras-chave: resistência de plantas daninhas, amendoim-bravo, fomesafen.

\begin{abstract}
Three trials were carried out to verify if the site of formesafen, absorption leaves or soil, affects the efficacy of controling this herbicide in wild poinsettia biotypes resistant and susceptible to the product; and to determine which plant structures are more important for fomesafen absorption. In the first two trials, fomesafen dose-response was evaluated on biotypes susceptible and resistant to PROTOX inhibitors, in the pre (first trial) and post emergence (second trial) applications. In a third trial, different deposition sites of fomesafen were evaluated using the double pot system to verify the structures of wild poinsettia plants which were most important to fomesafen absorption. Overall, the results indicated that shoot absorption of fomesafen was more limited on wild poinsettia biotypes with PROTOX resistance than on susceptible ones and that these differences between biotypes were less important when applied in pre-emergence. When applied to soil, fomesafen efficacy increased when the herbicide was placed near wild poinsettia shoots than close to their roots. These results support the hypothesis that leaf differences between resistant and susceptible plants may limit fomesafen absorption on biotypes resistant to PROTOX inhibitors.
\end{abstract}

Keywords: weed resistance, wild poinsettia, fomesafen.

Recebido para publicação em 25.3.2008 e na forma revisada em 18.2.2009.

2 Engoํ-Agr ${ }^{0}$, Dr., Professor do Curso de Agronomia da Universidade Tecnológica Federal do Paraná (UTFPR), Campus Pato Branco, Via do Conhecimento, km 01, Caixa Postal 571, 85503-390 Pato Branco-PR; ${ }^{3}$ Engo-Agr ${ }^{\circ}$, Dr., Professor da UFRGS, Caixa Postal 15100, 91540-000 Porto Alegre-RS; ${ }^{4}$ Eng--Agr ${ }^{0}$, Dr., Professor da UFSM, 97110-900 Santa Maria-RS; ${ }^{5}$ Engo-Agro ${ }^{\circ}$, UTFPR, Campus Pato Branco; ${ }^{6}$ Acadêmico do Curso de Agronomia da UTFPR, Campus Pato Branco. 


\section{INTRODUÇÃO}

A leiteira ou amendoim-bravo (Euphorbia heterophylla) apresenta germinação a campo de forma escalonada, grande produção de sementes e velocidade de crescimento elevada (Kissmann \& Groth, 1992; Vidal \& Trezzi, 2000), características que a tornam muito competitiva e de dificil controle. Desde a década de 1990, foram detectados no Brasil biótipos de leteira resistentes a herbicidas inibidores da ALS (Gazziero et al., 1998; Vidal \& Merotto Jr., 1999). Levantamentos realizados demonstraram que a resistência de leiteira a inibidores da ALS tornou-se bastante disseminada em áreas cultivadas com soja e outros cereais nos Estados do Sul do Brasil (Vidal et al., 2004; Felippi et al., 2004; Trezzi et al., 2005). Em 2004, foi confirmada resistência múltipla a herbicidas inibidores da acetolactato sintase (ALS) e da protoporfirinogênio oxidase (PROTOX) em dois biótipos de leiteira da região sudoeste do Paraná (Trezzi et al., 2005, 2006), em áreas de lavoura onde se utilizaram herbicidas desses mecanismos de ação por vários anos. Para conseguir controle mais efetivo desses biótipos nas áreas infestadas, os agricultores passaram a utilizar soja com gene RR e a intensificar os sistemas de rotação com milho.

Trabalhos realizados com o objetivo de determinar as melhores alternativas de manejo para os biótipos com resistência múltipla a inibidores da ALS e PROTOX demonstraram que herbicidas inibidores da PROTOX aplicados em pós-emergência, como fomesafen, lactofen, acifluorfen e flumiclorac, não controlaram biótipo com resistência simultânea, enquanto os herbicidas sulfentrazone e flumioxazin (também inibidores da PROTOX), aplicados em pré-emergência, exerceram controle eficiente. Esse efeito não foi observado, no entanto, na aplicação dos herbicidas inibidores da ALS, pois o biótipo foi resistente às aplicações em pré e pós-emergência (Trezzi et al., 2005). Dessa forma, passou-se a suspeitar que o mecanismo que determina a resistência a inibidores da PROTOX, nos biótipos de leiteira com resistência múltipla, estaria relacionado ao mecanismo de absorção dos herbicidas pelas plantas.

No mundo, atualmente, são encontradas apenas três espécies (Amaranthus rudis,
Ambrosia artemisiifolia e Euphorbia heterophylla) e cinco biótipos de plantas daninhas com resistência a inibidores da PROTOX. Curiosamente, todos os casos relatados apresentam resistência a mais de um mecanismo de ação herbicida, e também todos apresentam resistência a inibidores da ALS e PROTOX, embora dois biótipos apresentem resistência a três mecanismos de ação (Heap, 2008). Em estudo em que se verificou a suscetibilidade de caruru (A. rudis) às aplicações em pré e pósemergência de acifluorfen, azafenidin, flumioxazin, fomesafen, lactofen, oxyfluorfen e sulfentrazone, Falk et al. (2006) constatraram maior ação em pré-emergência de todos os herbicidas citados, o que demonstra comportamento similar ao dos dados inicialmente obtidos no Brasil, com os biótipos de leiteira. Esse trabalho também demonstrou maiores niveis de controle das plantas de A. rudis em aplicações em pós-emergência em estádio precoce, relativamente às aplicações em estádio mais avançado das plantas.

A base da seletividade de herbicidas inibidores da enzima PROTOX em espécies tolerantes pode ser atribuída à absorção e translocação minimas do herbicida, ao seqüestro de herbicida ou à concentração aumentada da enzima PROTOX mitocondrial, que serve como redutor para o excesso de protoporfirinogênio no citoplasma (Higgins et al., 1988; Matsumoto et al., 1999; Warabi et al., 2001). Herbicidas inibidores da PROTOX apresentam diferenças de absorção entre espécies de plantas, mas a translocação geralmente é limitada (Vanstone \& Stobbe, 1978; Ritter \& Coble, 1981; Higgins et al., 1998; Unland et al., 1999).

A tolerância de soja a acifluorfen foi explicada pela absorção e translocação menos rápidas e pelo metabolismo mais acentuado nessa espécie, em relação a $A$. artemisiifolia e Xanthium pensylvanicum (Ritter \& Coble, 1981). A tolerância da soja a flumiclorac também se deve a um somatório da reduzida absorção e translocação e elevada detoxificação desse herbicida, ao passo que a tolerância de milho é devida à reduzida retenção foliar do herbicida e à sua elevada metabolização (Fausey \& Renner, 2000).

A absorção de herbicidas pode ser afetada pelo local de deposição do produto. A absorção 
pela parte aérea é influenciada por características da superfície foliar, como composição, espessura e arranjo da cutícula, pelas condições do ambiente e pelas características físicoquímicas do herbicida (Vidal, 2002). A absorção de herbicidas aplicados em pré-emergência é influenciada principalmente por barreiras anatômico-fisiológicas à passagem dos herbicidas e por características físico-químicas destes. Em algumas espécies, os herbicidas que chegam ao solo são absorvidos preferencialmente pelo sistema radicular das plantas, enquanto em outras eles são absorvidos sobretudo pelas partes aéreas emergentes, como o hipocótilo, epicótilo e coleóptilo (Eshel \& Predeville, 1967).

Os objetivos deste trabalho foram verificar se o local de aplicação de fomesafen, folhas ou solo, afeta a eficácia de fomesafen em biótipos de $E$. heterophylla resistente e suscetivel a ele mesmo; e determinar quais estruturas da planta são mais importantes no processo de absorção desse herbicida.

\section{MATERIAL E MÉTODOS}

Três experimentos foram conduzidos em vasos, em casa-de-vegetação do Curso de Agronomia da UTFPR, campus Pato Branco-PR, em delineamento completamente casualizado, com quatro repetições.

Os dois primeiros experimentos foram implantados em dezembro de 2006, em arranjo fatorial $2 \times 7$. No primeiro experimento o fomesafen foi aplicado em pré-emergência e, no segundo, em pós-emergência. Em ambos os experimentos, o primeiro fator foi composto pelos biótipos de leiteira (com e sem resistência), e o segundo, representado pelos niveis de fomesafen $(0,120,240,480,960,1.920 \mathrm{e}$ $3.840 \mathrm{~g} \mathrm{ha}^{-1}$ na aplicação em pré-emergência e $0,50,100,200,400,800$ e $1.600 \mathrm{~g} \mathrm{ha}^{-1}$ na aplicação em pós-emergência). Convém ressaltar que o biótipo de leiteira resistente aos inibidores da PROTOX utilizados em todos os experimentos também apresenta resistência aos herbicidas inibidores da enzima ALS e suas sementes foram obtidas a partir de experimentos prévios realizados pelo Curso de Agronomia da UTFPR.

O solo utilizado nos vasos foi coletado na área experimental da UTFPR, homogeneizado, peneirado em peneira de malha de $3 \mathrm{~mm}$ e depositado em vasos com capacidade para $1.000 \mathrm{~cm}^{3}$. A aspersão dos herbicidas foi feita no mesmo dia nos dois experimentos, com pulverizador manual pressurizado a $\mathrm{CO}_{2}$, utilizando-se bicos leque 110.02 e volume de calda de $180 \mathrm{~L} \mathrm{ha}^{-1}$. Nesses experimentos, foram depositadas 15 sementes de leiteira em cada vaso. No experimento em pré-emergência, os herbicidas foram aspergidos logo após a semeadura. Já no experimento em pós-emergência, procedeu-se ao desbaste das plantas, deixando cinco plantas por vaso, e aspergiu-se fomesafen no momento em que as plantas atingiram o estádio de duas folhas cotiledonares mais duas folhas verdadeiras (denominado popularmente de "estrelinha").

O terceiro experimento foi implantado em março de 2007, utilizando-se o método do vaso duplo, que consiste no uso de vasos sobrepostos, para avaliar o local predominante de absorção de herbicida pelas plantas (Eshel \& Predeville, 1967). O experimento foi arranjado em esquema fatorial $2 \times 4 \times 3$, em que o primeiro fator foi representado pelos biótipos de leiteira resistente e suscetivel; o segundo, por diferentes posicionamentos do solo contendo o herbicida fomesafen (porções inferior e superior tratadas, superior tratada e inferior não-tratada, superior não-tratada e inferior tratada e testemunha sem herbicida); e o terceiro, por niveis de fomesafen (23, 46 e $93 \mathrm{~g} \mathrm{~kg}^{-1}$ de solo). Sementes de leiteira, provenientes de plantas $\mathrm{R}$ e $\mathrm{S}$, foram pré-germinadas em câmara de crescimento e transferidas para vasos 48 horas depois. Foi empregada uma mistura do mesmo solo utilizado nos primeiros experimentos e do substrato "Plantmax". Essa mistura foi colocada sobre lona plástica, em camada uniforme ( $2 \mathrm{~cm}$ de altura), sobre a qual foi aspergido fomesafen nas concentrações supramencionadas, utilizando-se o mesmo equipamento e tecnologia de aplicação do primeiro e segundo experimentos. Essa mistura e o herbicida foram revolvidos para uniformização da concentração do herbicida, e a mistura foi utilizada para preencher os tratamentos com herbicida. Posicionou-se cada plântula obtida pelo processo de pré-germinação junto a pequenos orificios no fundo do vaso superior do conjunto de vasos sobrepostos, de forma que o sistema radicular atravessasse o fundo do vaso, em direção ao vaso inferior, enquanto a 
parte aérea crescia em direção ao vaso na posição superior. Foram depositadas sete plântulas de leiteira por vaso. Os diferentes ambientes contendo fomesafen foram obtidos pelas combinações de enchimento com solo dos vasos superior e inferior: a) vasos superior e inferior com solo tratado; b) vaso superior com solo tratado e inferior com solo não-tratado; c) vaso superior com solo não-tratado e inferior com solo tratado; e d) vasos superior e inferior com solo não-tratado.

Nos dois primeiros experimentos, foram determinados os niveis de controle de leiteira aos 14 e 21 DAA, por meio de escala de 0 a $100 \%$. No terceiro experimento, foi avaliado o controle aos 10 e 18 DAA. Os dados foram submetidos à análise da variância pelo teste F. Em caso de significância dos fatores principais ou das interações, os dados qualitativos foram comparados pelo teste de Tukey a 5\%. No primeiro e segundo experimentos, a relação entre variável dependente e os níveis dos herbicidas foi ajustada através de equação logística de quatro parâmetros (Seefeldt et al., 1995), com auxílio do software Sigmaplot. No terceiro experimento, a relação entre variável dependente e os niveis dos herbicidas foi ajustada por meio de regressão polinomial.

\section{RESULTADOS E DISCUSSÃO}

Para os resultados de controle por avaliação visual tanto no experimento em pré quanto no experimento em pós-emergência, não houve interação entre biótipo e dose, havendo

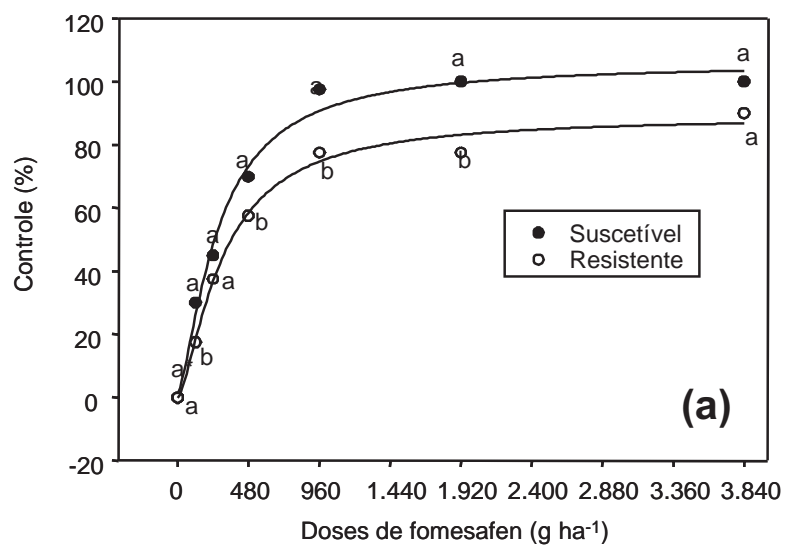

significância do efeito simples de biótipo e de dose. Em geral, nos dois experimentos, observou-se aumento do controle com a elevação da dose de fomesafen, com valores maiores para o biótipo suscetível do que para o com resistência múltipla (Figuras 1 e 2). Não houve diferenças substanciais nos niveis de controle para cada biótipo, entre as datas de avaliação, nos dois experimentos (Figuras 1 e 2).

Os niveis de controle exercidos por fomesafen em pré-emergência, nas doses de $960,1.920$ e $3.840 \mathrm{~g} \mathrm{ha}^{-1}$, situaram-se próximos a $100 \%$ para o biótipo suscetível, sendo em média $24 \%$ superiores aos obtidos no biótipo resistente. Aplicado ao solo, o fomesafen a $240 \mathrm{~g} \mathrm{ha}^{-1}$ proporcionou niveis de controle deficientes para ambos os biótipos (apenas 40 a 45\%) (Figura 1).

As doses de 800 e $1.600 \mathrm{~g} \mathrm{ha}^{-1}$ de fomesafen, no experimento em pós-emergência, propiciaram controle entre 90 e $98 \%$ no biótipo suscetivel, sendo muito superiores aos obtidos no biótipo resistente (controle médio de apenas 40\%) (Figura 2). Plantas do biótipo de leiteira resistente aos herbicidas sofreram injúria de fomesafen aplicado nas folhas mesmo em dose recomendada pelo fabricante $\left(250 \mathrm{~g} \mathrm{ha}^{-1}\right)$, indicando que a resistência não é absoluta, o que está de acordo com os resultados anteriormente obtidos por Trezzi et al. (2006). Aplicado em pós-emergência, o fomesafen na dose de $200 \mathrm{~g} \mathrm{ha}^{-1}$ (próximo à recomendada) exerceu cerca de $80 \%$ de controle das plantas do biótipo suscetivel. No entanto, plantas do biótipo de

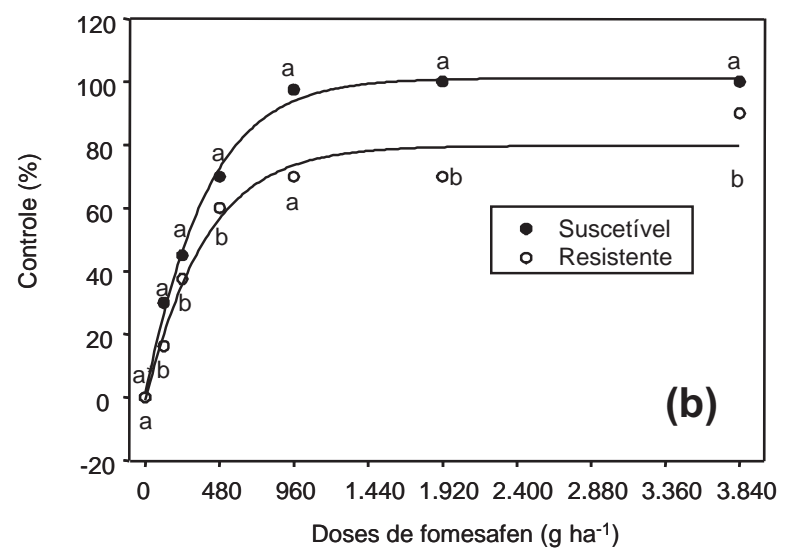

* Médias seguidas pela mesma letra dentro de cada concentração de fomesafen não diferem pelo teste de Tukey a 5\%.

Figura 1 - Controle (\%) de plantas de E. heterophylla dos biótipos suscetível e resistente, em função das doses de fomesafen em pré-emergência, aos 14 (a) e 21 dias após a aplicação (b). 
leiteira resistente não foram controladas (menos de $30 \%$ de controle) (Figura 2).

As diferenças entre os níveis de controle de plantas do biótipo suscetível, quando o fomesafen foi aplicado em pré e pós-emergência, ocorreram, provavelmente, devido à adsorção do produto ao solo e à conseqüente redução da disponibilidade do herbicida para as plantas.

No experimento em pré-emergência, aos 14 DAA, os valores de $I_{50}$ foram de 276 e 306, respectivamente, para os biótipos suscetivel e resistente (Tabela 1). Aos 21 DAA, os valores de $I_{50}$ foram de 478 e 741 , para suscetivel e resistente, respectivamente. Esses valores determinaram fatores de resistência (FRs) no experimento em pré-emergência de 1,1 aos 14 DAA e de 1,5 aos 21 DAA (Tabela 1). No experimento em pós-emergência, aos 14 DAA, os valores de $I_{50}$ foram de 172 e 250, para os biótipos suscetível e resistente, respectivamente (Tabela 2). Aos 21 DAA, os valores de $I_{50}$ foram de 478 e 741 , para suscetivel e resistente, respectivamente. Os FRs no experimento em pós-emergência foram, respectivamente, de 1,4 aos 14 DAA e 2,1 aos 21 DAA (Tabela 2).

Os valores de FR numericamente superiores no experimento em pós-emergência, em relação ao experimento em pré, ratificam os baixos niveis de controle do biótipo resistente em pós-emergência, descritos anteriormente. Ao avaliarem a matéria seca de plantas de leiteira do mesmo biótipo utilizado no presente experimento, em resposta a diferentes niveis de fomesafen em pós-emergência, Trezzi et al. (2005) constataram valores de FR de 39. A maior amplitude de doses utilizada naquele experimento (mínima de $300 \mathrm{~g} \mathrm{ha}^{-1}$ e máxima de $4.800 \mathrm{~g} \mathrm{ha}^{-1}$ ) poderia explicar em parte os valores de FR mais elevados.
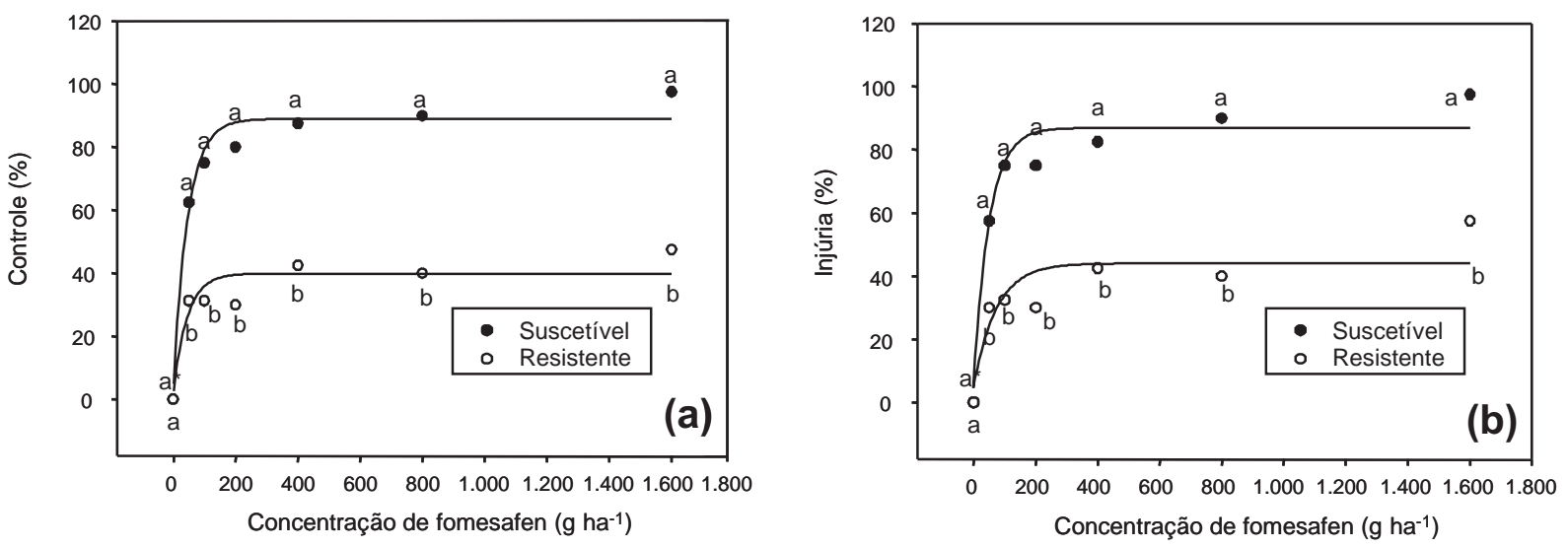

* Médias seguidas pela mesma letra dentro de cada concentração de fomesafen não diferem pelo teste de Tukey a 5\%.

Figura 2 - Controle (\%) de plantas de E. heterophylla dos biótipos suscetível e resistente, em função das doses de fomesafen em pós-emergência, aos 14 (a) e aos 21 dias após a aplicação (b).

Tabela 1 - Parâmetros a, b, c, d da equação logística dose-resposta do experimento em pré-emergência, nas avaliações efetuadas aos 14 e 21 dias após a aplicação

\begin{tabular}{|l|c|c|c|c|c|c|c|c|}
\hline \multirow{3}{*}{ Biótipo } & \multicolumn{9}{|c|}{ Período de avaliação } \\
\cline { 2 - 9 } & \multicolumn{4}{|c|}{14 DAA } & \multicolumn{4}{c|}{21 DAA } \\
\cline { 2 - 9 } & $a^{\underline{1} /}$ & $b$ & $c$ & $d$ & $a$ & $b$ & $c$ & $d$ \\
\hline Suscetível & 104,6 & $-1,4$ & 275,6 & 1,2 & 507,8 & 339,3 & $-477,7$ & $-406,7$ \\
\hline Resistente & 89,3 & $-1,4$ & 305,6 & $-0,2$ & 718,3 & 358,3 & $-741,1$ & $-638,6$ \\
\hline Fator de resistência & & & 1,1 & & & & 1,5 & \\
\hline
\end{tabular}

1/ $a=$ assíntota superior da equação; $b=$ declividade da curva; $c=$ nível de herbicida que produz $50 \%$ de controle $\left(\mathrm{I}_{50}\right) ; d=$ assíntota inferior da equação. 
Tabela 2 - Parâmetros a, b, c, d da equação logística dose-resposta do experimento em pós-emergência, nas avaliações efetuadas aos 14 e 21 dias após a aplicação

\begin{tabular}{|c|c|c|c|c|c|c|c|c|}
\hline \multirow{3}{*}{ Biótipo } & \multicolumn{8}{|c|}{ Período de avaliação } \\
\hline & \multicolumn{4}{|c|}{14 DAA } & \multicolumn{4}{|c|}{$21 \mathrm{DAA}$} \\
\hline & $a^{\underline{1} /}$ & $b$ & $c$ & $d$ & $a$ & $b$ & $c$ & $d$ \\
\hline Suscetível & $3.650,0$ & 45,8 & $-171,9$ & $-3.561,2$ & $4.674,2$ & 49,5 & $-199,2$ & $-4.587,2$ \\
\hline Resistente & $1.005,4$ & 44,7 & $-250,2$ & $-9.965,6$ & $13.465,7$ & 73,2 & $-426,8$ & $-13.421,6$ \\
\hline Fator de resistência & & & 1,4 & & & & 2,1 & \\
\hline
\end{tabular}

1/ $a=$ assíntota superior da equação; $b=$ declividade da curva; $c=$ nível de herbicida que produz $50 \%$ de controle $\left(\mathrm{I}_{50}\right) ; d=$ assíntota inferior da equação.

As maiores diferenças de controle entre os biótipos resistente e suscetivel no experimento conduzido em pós-emergência, em relação àquele em pré-emergência, podem indicar a existência de barreiras mais importantes para a absorção e/ou translocação de fomesafen na parte aérea das plantas ou que estas barreiras são mais facilmente superadas pela aplicação de fomesafen em pré-emergência. A presença de cutícula nas células jovens absorventes de raízes é inexistente ou reduzida, em contraste com os órgãos aéreos das plantas (Vidal, 2002; Rodrigues, 2003; Silva et al., 2007), e talvez seja pequena também a camada cuticular nas partes aéreas presentes no solo das plantas em emergência, o que poderia explicar o menor efeito de fomesafen no biótipo resistente em relação ao suscetivel na aplicação em pós-emergência, comparada à aplicação em pré-emergência. Outra possibilidade, que não pode ser descartada, é de que tecidos mais jovens poderiam ter maior capacidade de metabolização de inibidores da PROTOX do que tecidos mais velhos, além de possuir plasmodesmos com maior diâmetro e com translocação mais efetiva de moléculas com tamanho de até $1 \mathrm{kDa}$, como a da maioria dos herbicidas (Concenço et al., 2007), facilitando sua dispersão por maior quantidade de células.

Comparando o efeito dos herbicidas acifluorfen, azafenidin, flumioxazin, fomesafen, lactofen, oxyfluorfen e sulfentrazone aplicados em pré e pós-emergência sobre biótipo de caruru (A. rudis) resistente a inibidores da PROTOX, Falk et al. (2006) demonstraram maior ação em pré-emergência de todos os herbicidas citados, similarmente aos resultados obtidos no presente experimento. Esses autores também constataram maiores niveis de controle de $A$. rudis em estádios precoces de desenvolvimento, em relação a estádios mais tardios.

A literatura atribui a base da seletividade de herbicidas inibidores da enzima PROTOX em espécies tolerantes a quatro fenômenos: absorção e translocação reduzidas, sequestro de herbicida ou concentração aumentada da enzima PROTOX mitocondrial, que serve como redutor para o excesso de protoporfirinogênio no citoplasma (Higgins et al., 1988; Matsumoto et al., 1999; Warabi et al., 2001).

Este trabalho sugere que a estratégia de aplicar herbicidas inibidores da PROTOX em pré-emergência pode ser mais adequada para o seu controle. No entanto, a dose necessária para obter $80 \%$ de controle do biótipo suscetivel na modalidade de pré-emergência é de cerca de $600 \mathrm{~g}$ fomesafen ha $^{-1}$ (cerca de 2,4 vezes a dose recomendada pelo fabricante); para o biótipo resistente, há necessidade de doses de fomesafen acima de $1.920 \mathrm{~g} \mathrm{ha}^{-1}$, ou seja, cerca de 7,7 vezes a dose recomendada em pósemergência. No Brasil, o fomesafen não apresenta registro em pré-emergência. A utilização de doses tão elevadas desse herbicida representaria custo muito elevado para os agricultores e demandaria informações sobre o impacto ambiental causado. Estudos com outros herbicidas inibidores da PROTOX recomendados na cultura da soja, em préemergência das plantas, como sulfentrazone e flumioxazin, deveriam avaliar a sua eficácia sobre biótipos de leiteira suscetiveis e resistentes, já que herbicidas com esse mecanismo de ação são alternativas fundamentais para o manejo de plantas daninhas em soja. 
No terceiro experimento, os resultados das avaliações visuais de controle aos 10 e 18 DAA de fomesafen apresentaram interação significativa entre os fatores biótipo e posicionamento do fomesafen, biótipo e concentração do fomesafen e posicionamento do fomesafen e concentração do herbicida. A análise do controle entre os biótipos de leiteira, dentro de cada posicionamento do herbicida no sistema vaso/sobre vaso, mostrou que apenas nos posicionamentos de vaso inferior com solo nãotratado/vaso superior com solo tratado (abaixo sem/acima com herbicida), na avaliação aos 10 DAA, e inferior com solo tratado e superior não-tratado (abaixo com/acima sem herbicida), na avaliação aos 18 DAA, houve diferenças de controle entre o biótipo suscetivel e o resistente (Tabela 3). Não houve diferença entre os biótipos para as demais combinações de posicionamento do herbicida.

A comparação entre os diferentes posicionamentos dentro de cada biótipo demonstra, na avaliação aos 10 DAA, que os níveis de controle nos sistemas inferior com/superior com e inferior sem/superior com não diferiram entre si (Tabela 3), porém ambos foram superiores aos do sistema inferior com/superior sem. Já na avaliação aos 18 DAA, os três posicionamentos de fomesafen mostraram resultados distintos entre si, embora a diferença entre o tratamento inferior com/superior com e inferior sem/superior com tenha sido bem menos expressiva (18\% na média dos biótipos) do que entre os tratamentos inferior $\mathrm{sem} /$ superior com e inferior com/superior sem (em média, 80\%) (Tabela 3). Conclui-se, portanto, que o posicionamento de fomesafen no solo, junto à parte aérea das plântulas de leiteira em emergência, resulta em niveis de controle superiores aos observados quando ele está posicionado junto às raízes delas.

$\mathrm{Na}$ avaliação aos 10 DAA, houve diferenças significativas de controle entre os biótipos apenas nas concentrações de fomesafen de 0,23 e $0,92 \mathrm{~g} \mathrm{~kg}^{-1}$ solo (Figura 3a). Na concentração mais baixa, esse herbicida controlou melhor o biótipo suscetível do que o biótipo resistente. Na dose mais elevada, o fomesafen controlou mais eficientemente o biótipo resistente (90\%), em comparação ao suscetivel (75\%). Aos 18 DAA (Figura 3b), os niveis de controle foram menos expressivos do que aos 10 DAA. Na dose de $0,46 \mathrm{~g} \mathrm{~kg}^{-1}$ de solo, o biótipo suscetivel foi mais bem controlado do que o resistente. Contudo, na concentração de $0,92 \mathrm{~g} \mathrm{~kg}^{-1}$ de solo, as plantas resistentes foram mais bem controladas. Diferenças um pouco mais expressivas entre os biótipos foram detectadas no experimento de curvas de doseresposta em pré-emergência (Figura 1), provavelmente porque os dados do terceiro experimento representam a média de três combinações de posicionamentos de herbicidas diferentes.

Na primeira avaliação entre posicionamentos dentro de concentração do fomesafen, aos 10 DAA, o controle de leiteira não diferiu entre os sistemas inferior com/ superior com e inferior sem/superior com (Figura 4a). Esses tratamentos foram mais efetivos no controle de leiteira do que o tratamento em que o fomesafen foi posicionado apenas embaixo das plantas. Nesse último tratamento, a concentração mais elevada do fomesafen no solo resultou em apenas $50 \%$ de controle. Aos 18 DAA, os níveis de controle das plantas foram

Tabela 3 - Controle de plantas de E. heterophylla aos 10 e 18 dias após a aplicação dos tratamentos, em função de diferentes biótipos e posicionamentos no solo, na média das concentrações do fomesafen

\begin{tabular}{|c|c|c|c|c|c|c|}
\hline \multirow{2}{*}{ Biótipo } & \multicolumn{5}{|c|}{ Controle (\%) } \\
\cline { 2 - 7 } & \multicolumn{5}{|c|}{ Posição do herbicida no sistema de vasos } \\
\cline { 2 - 7 } & \multicolumn{2}{|c|}{ Inferior com/Superior sem } & Inferior sem /Superior com & \multicolumn{3}{c|}{ Inferior com /Superior com } \\
\cline { 2 - 7 } & $10 \mathrm{DAA}$ & $18 \mathrm{DAA}$ & $10 \mathrm{DAA}$ & $18 \mathrm{DAA}$ & \multicolumn{1}{|c|}{$10 \mathrm{DAA}$} & $18 \mathrm{DAA}$ \\
\hline Suscetível & $9 \mathrm{~b}^{\underline{1} /} \mathrm{A}$ & $3 \mathrm{cB}$ & $62 \mathrm{aA}$ & $41 \mathrm{~b} \mathrm{~A}$ & $67 \mathrm{aA}$ & $50 \mathrm{aA}$ \\
\hline Resistente & $20 \mathrm{bA}$ & $13 \mathrm{cA}$ & $51 \mathrm{aB}$ & $38 \mathrm{~b} \mathrm{~A}$ & $64 \mathrm{aA}$ & $47 \mathrm{aA}$ \\
\hline
\end{tabular}

1/ Dentro da mesma data de avaliação, médias seguidas da mesma letra minúscula na linha indicam ausência de diferenças significativas entre posicionamentos de fomesafen e médias seguidas da mesma letra maiúscula na coluna indicam ausência de diferenças entre biótipos, pelo teste de Tukey a $5 \%$. 
reduzidos em relação a 10 DAA, especialmente nas concentrações intermediárias do herbicida. Os niveis de controle nos três posicionamentos do fomesafen foram distintos, embora a diferença do sistema inferior com/superior com em relação ao inferior sem/superior com tenha sido bem menos expressiva (em média, $23 \%$ ), em relação à diferença entre os sistemas inferior sem/superior com e inferior com/ superior sem (em média, 65\%). No tratamento inferior $\mathrm{com} /$ superior sem, a concentração mais elevada do herbicida no solo resultou em apenas $25 \%$ de controle (Figura $4 b$ ).

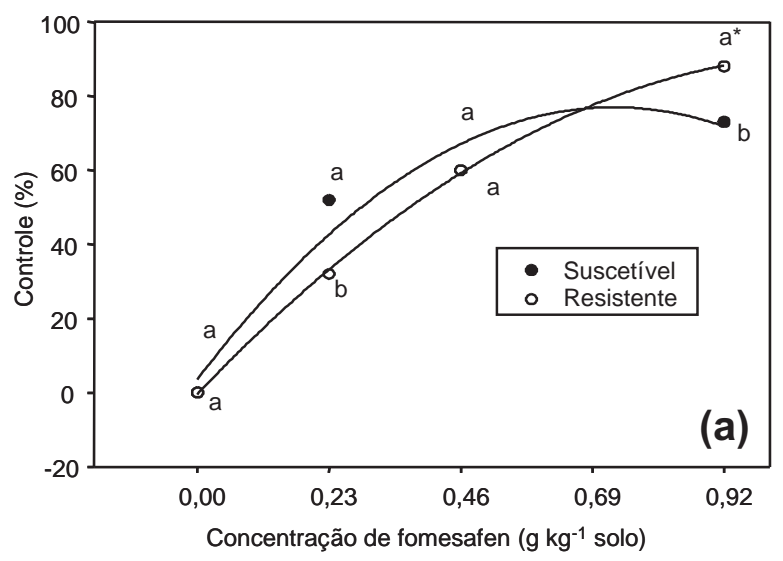

O conjunto de resultados demonstra, portanto, que, além de concentrações de fomesafen adequadas, o controle eficiente de biótipos resistentes e suscetiveis de leiteira requer que o herbicida seja absorvido pela parte aérea emergente das plântulas, havendo importância secundária do sistema de raízes no controle exercido por fomesafen. A monografia escrita por Vencill (2002) mostra que o fomesafen é absorvido, de forma geral, pelo sistema radicular das plantas, sem, no entanto, mencionar a importância da sua absorção pelas partes aéreas emergentes.

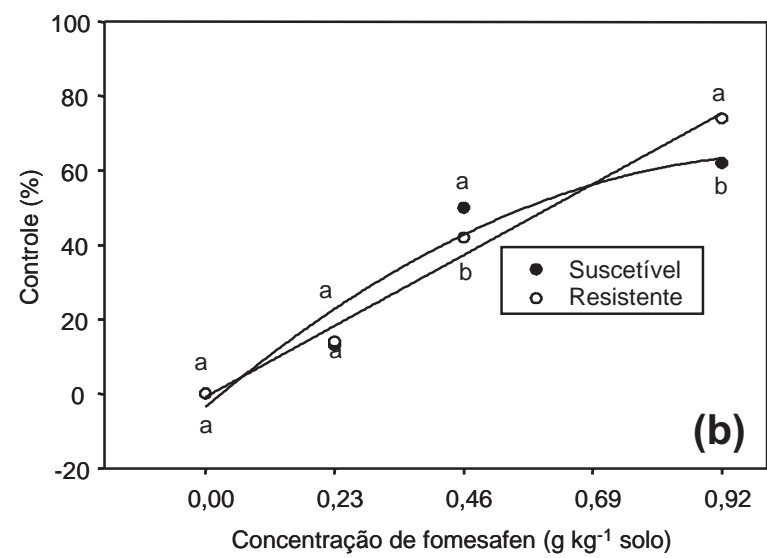

* Médias seguidas pela mesma letra dentro de cada concentração de fomesafen não diferem pelo teste de Tukey a 5\%.

Figura 3 - Controle de E. heterophylla nos biótipos suscetível e resistente aos 10 (a) e 18 dias (b) após a aplicação de fomesafen em pré-emergência, na média das posições do herbicida no solo.
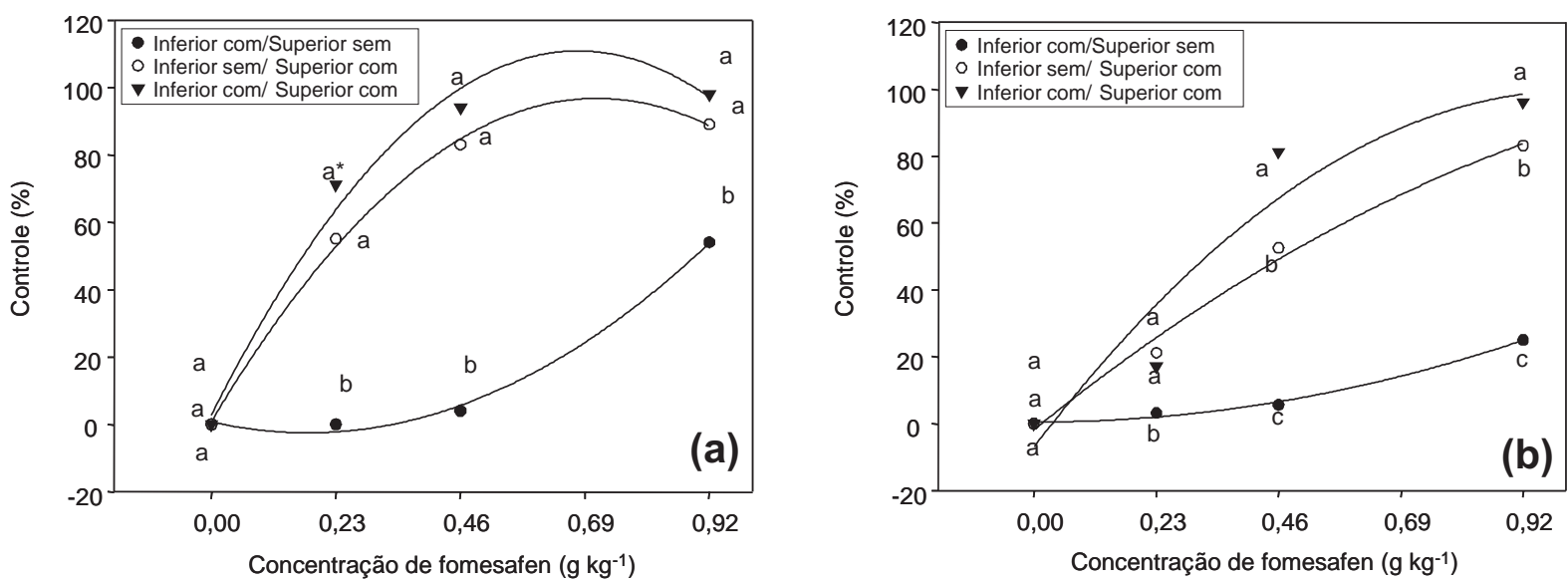

* Na mesma dose, médias seguidas da mesma letra minúscula não diferem pelo teste de Tukey a 5\%.

Figura 4 - Controle de E. heterophylla aos 10 (a) e 18 dias (b) após a aplicação de fomesafen em função das suas posições no sistema vaso/sobrevaso e das concentrações utilizadas, na média dos biótipos. 
Trabalhos realizados por Blackman \& Deveson (1990) e Vidal \& Fleck (1993) comprovaram a importância da absorção de herbicidas inibidores de carotenoides pelo hipocótilo e epicótilo para o controle de espécies dicotiledôneas. Outros trabalhos demonstraram a importância da absorção de herbicidas pelo coleóptilo para controle de espécies gramíneas (Knake et al., 1967; Knake \& Wax, 1968).

No sistema de semeadura direta de culturas de lavoura, presente na maioria das propriedades do Sul do Brasil, a maior parte das sementes de plantas daninhas fica depositada próxima à superfície do solo, e as partes aéreas emergentes de leiteira absorverão fomesafen depositado nessa região. Fatores que deslocam herbicidas da camada superficial do solo, como a erosão superficial, ou que aumentam sua retenção nesta camada, como a baixa disponibilidade hídrica e o aumento dos teores de matéria orgânica, tendem a diminuir a disponibilidade de produto para as plantas daninhas e, portanto, reduzir a eficiência de controle destas. Assim, está clara a importância de se conhecer o local preferencial de absorção de herbicidas pelas espécies daninhas.

O presente trabalho demonstra maiores diferenças de sensibilidade a fomesafen entre os biótipos de leiteira resistente a PROTOX e suscetível em aplicações em pós-emergência, em relação à aplicação em pré-emergência. Esse comportamento diferencial pode estar relacionado ao mecanismo de resistência a inibidores da PROTOX no biótipo resistente. Como as doses do fomesafen necessárias para controlar o biótipo resistente são muito elevadas, estudos devem ser efetuados com outros herbicidas inibidores da PROTOX com potencial para utilização em pré-emergência, em culturas comerciais no Brasil. Para se obter boa eficiência de controle do biótipo de leiteira resistente aos herbicidas inibidores da PROTOX, em sistema de semeadura direta, os herbicidas inibidores da PROTOX devem ser aplicados em doses adequadas e posicionados na camada superficial do solo.

\section{AGRADECIMENTOS}

Ao CNPq e à Fundação Araucária, pelo apoio a este trabalho.

\section{LITERATURA CITADA}

BLACKMAN, P. G.; DEVESON, M. R. The origins of selectivity and performance of a new pre-emergence bleaching herbicide. Part II: Plant and environmental factors influencing biological activity. Pestic. Sci., v. 28, n. 2, p. $143-156,1990$

CONCENÇO, G. et al. Plasmodesmos: transporte simplástico de herbicidas na planta. Planta Daninha, v. 25, n. 2, p. 423-432, 2007.

ESHEL, Y.; PREDEVILLE, G. N. A technique for studying roots vs. shoot uptake of soil-applied herbicides. Weed Res., v. 7, n. 3, p. 242-245, 1967

FALK, J. et al. Protox-resistant common waterhemp (Amaranthus rudis) response to herbicides applied at different growth stages. Weed Sci., v. 54, n.4, p. 793-799, 2006.

FAUSEY, J. C.; RENNER, K. A. Physiological basis for CGA-248757 and flumiclorac selectivity in five plant species. Weed Sci., v. 48, n. 4, p. 405-411, 2000.

FELIPPI, C. L. et al. Ocorrência de biótipos de Euphorbia heterophylla e Bidens spp resistentes a inibidores da enzima ALS e da PROTOX, no sudoeste e oeste do Paraná e oeste de Santa Catarina. In: CONGRESSO BRASILEIRO DA CIÊNCIA DAS PLANTAS DANINHAS, 24., 2004, Águas de São Pedro-SP. Resumos... Piracicaba: SBCPD, 2004.

GAZZIERO, D. L. P. et al. Resistência de amendoim-bravo aos herbicidas inibidores da ALS. Planta Daninha, v. 16, n. 2, p. 117-125, 1998.

HEAP, I. International survey of resistant weeds Disponível em: <http://www. weedsciencie.org/in.asp> Acesso em: 15 fev. de 2008.

HIGGINS, J. M. et al. Absorption, translocation, and metabolism of acifluorfen and lactofen in pitted morning glory (Ipomoea lacunosa) and ivy leaf moringglory (Ipomoea hederaceae). Weed Sci., v. 36, n. 2, p. 141-145, 1988.

KISSMANN, K.; GROTH, D. Plantas infestantes e nocivas. São Paulo: Basf Brasileira, 1992. Tomo II. p. 191-195.

KNAKE, E. L. et al. Soil incorporation and site of uptake of preemergence herbicides. Weeds, v. 15, n. 3, p. 228-232, 1967.

KNAKE, E. L.; WAX, L. M. The importance of shoot of giant foxtail for uptake of preemergence herbicides. Weed Sci., v. 16, n. 3, p. 393-395, 1968.

MATSUMOTO, H. et al. Basis for common chickweed (Stellaria media) tolerance to oxyfluorfen. Pestic. Biochem. Physol., v. 64, n. 1, p. 47-53, 1999.

Planta Daninha, Viçosa-MG, v. 27, n. 1, p. 139-148, 2009 
RITTER, R. L.; COBLE, H. D. Penetration, translocation, and metabolism of acifluorfen in soybean (Glycine max), common ragweed (Ambrosia artemisiifolia), and common cocklebur (Xanthium pensylvanicum). Weed Sci., v. 29, n. 4, p. 474-480, 1981.

RODRIGUES, J. D. Fisiologia vegetal e sua importância na tecnologia de aplicação de defensivos. Biológico, v. 65, n. 1/2, p. 59-61, 2003.

SEEFELDT, S. S. et al. Log-logistic analysis of herbicide dose-response relationships. Weed Technol., v. 9, n. 2, p. $218-227,1995$

SILVA, J. F. et al. Herbicidas: absorção, translocação, metabolismo, formulação e misturas. In: SILVA, A. A.; SILVA, J. F. (Eds.). Tópicos em manejo de plantas daninhas. Viçosa, MG: Universidade Federal de Viçosa, 2007. 367 p.

TREZZI, M. M. et al. Multiple resistance of acetolactate synthase and protoporphyrinogen oxidase inhibitors in Euphorbia heterophylla biotypes. J. Environ. Sci. Health Part B, v. 40, n. 1, p. 101-109, 2005.

TREZZI, M. M. et al. Bioensaios para identificação de biótipos de Euphorbia heterophylla com resistência múltipla a inibidores da ALS e da PROTOX. Planta Daninha, v. 24, n. 3, p. 563-571, 2006.

UNLAND, D. R. et al. Interactions between imazamox and diphenylethers. Weed Sci., v. 47, n. 4, p. 462-466, 1999.
VANSTONE, D. E.; STOBBE, E. H. Root uptake, translocation, and metabolism of nitrofluorfen and oxyfluorfen by fababeans (Vicia faba) and green foxtail (Setaria viridis). Weed Sci., v. 26, n. 4, p. 389-392, 1978.

VENCILL, W. K. Herbicide handbook. 8.ed. Lawrence: Weed Science Society of America, 2002. 493 p.

VIDAL, R. A. Ação dos herbicidas. Porto Alegre: Ribas Vidal, 2002. v. 1.89 p.

VIDAL, R. A.; FLECK, N. G. Injúria potencial de herbicidas de solo ao girassol. I - Clomazone. Planta Daninha, v. 11, n. 1, p. 36-43, 1993.

VIDAL, R.A.; MEROTTO JR., A. Resistência de amendoim bravo (Euphorbia heterophylla L.) aos herbicidas inibidores da enzima acetolactato sintase. Planta Daninha, v. 17, n. 3 , p. $367-373,1999$

VIDAL, R. A.; TREZZI, M. M. Análise de crescimento de biótipos de leiteira (Euphorbia heterophylla) resistentes e suscetível aos herbicidas inibidores da ALS. Planta

Daninha, v. 18, n. 3, p. 427-433, 2000.

VIDAL, R. A. et al. A field survey of crop management practices and distribution of ALS resistant Euphorbia heterophylla in two states in Southern Brazil. Planta Daninha, v. 22, n. 3, p. 403-410, 2004.

WARABI, E. et al. Resistance of a soybean cell line to oxyfluorfen overproduction of mitochondrial protoporphyrinogen oxidase. Pest Manag. Sci., v. 57, n. 8, p. $743-748,2001$ 